\title{
Performance of a low-cost methane sensor for ambient concentration measurements in preliminary studies
}

\author{
W. Eugster ${ }^{1}$ and G. W. Kling ${ }^{2}$ \\ ${ }^{1}$ ETH Zurich, Institute of Agricultural Sciences, Universitätsstrasse 2, 8092 Zurich, Switzerland \\ ${ }^{2}$ University of Michigan, Department of Ecology \& Evolutionary Biology, Ann Arbor, MI 48109-1048, USA
}

Correspondence to: W. Eugster (eugsterw@ethz.ch)

Received: 29 February 2012 - Published in Atmos. Meas. Tech. Discuss.: 30 March 2012

Revised: 5 July 2012 - Accepted: 17 July 2012 - Published: 13 August 2012

\begin{abstract}
Methane is the second most important greenhouse gas after $\mathrm{CO}_{2}$ and contributes to global warming. Its sources are not uniformly distributed across terrestrial and aquatic ecosystems, and most of the methane flux is expected to stem from hotspots which often occupy a very small fraction of the total landscape area. Continuous time-series measurements of $\mathrm{CH}_{4}$ concentrations can help identify and locate these methane hotspots. Newer, low-cost trace gas sensors such as the Figaro TGS 2600 can detect $\mathrm{CH}_{4}$ even at ambient concentrations. Hence, in this paper we tested this sensor under real-world conditions over Toolik Lake, Alaska, to determine its suitability for preliminary studies before placing more expensive and service-intensive equipment at a given locality. A reasonably good agreement with parallel measurements made using a Los Gatos Research FMA 100 methane analyzer was found after removal of the strong sensitivities for temperature and relative humidity. Correcting for this sensitivity increased the absolute accuracy required for in-depth studies, and the reproducibility between two TGS 2600 sensors run in parallel is very good. We conclude that the relative $\mathrm{CH}_{4}$ concentrations derived from such sensors are sufficient for preliminary investigations in the search of potential methane hotspots.
\end{abstract}

\section{Introduction}

Although methane concentrations are much lower than those of carbon dioxide in the atmosphere, it is still the second most important greenhouse gas because its greenhouse warming potential is 20-25 times greater than that of $\mathrm{CO}_{2}$. In addition, $\mathrm{CH}_{4}$ is more dynamic than $\mathrm{CO}_{2}$ in part because its lifetime in the atmosphere is on the order of $10-12 \mathrm{yr}$, much shorter than that of $\mathrm{CO}_{2}$. While steady increases of $\mathrm{CH}_{4}$ in the atmosphere contribute to global warming, its sources are not uniformly distributed across terrestrial and aquatic ecosystems; often the highest methane fluxes come from localized hotspots, which may occupy only a very small area of the total landscape. In addition, recent scientific debates have centered on how $\mathrm{CH}_{4}$ dynamics may accelerate future global warming through feedback mechanisms, especially related to the warming of arctic ecosystems (Serreze and Francis, 2006; McGuire et al., 2006).

In the Arctic, such hotspots are generally associated with wetlands or shallow waters where sedge species with aerenchyma vent methane produced in the anoxic sediments to the atmosphere (Reeburgh et al., 1998). Lakes can be hotspots of methane emissions under certain circumstances during turnover or mixing events (Eugster et al., 2003). Often, large methane fluxes from lakes are associated with ebullition (DelSontro et al., 2010; Eugster et al., 2011); in the Arctic this is easily visible during the cold season thanks to bubbles trapped in the ice (Walter et al., 2006). One approach to find hotspots is to move a gas analyzer across the landscape and observe the concentration changes in the near-surface atmosphere that can be associated with a point source of methane emissions. So far, this was mostly done with sensors carried by helicopter (e.g., Karapuzikov et al., 1999; Zirnig et al., 2004; Dzikowski et al., 2009; Haifang et al., 2011), by small aircraft (e.g., Hiller et al., 2011), by ground based laser scanning (e.g., Gibson et al., 2006) or surface surveying with a field-portable flame-ionization detector (e.g., Schroth et al., 2012). All these approaches, however, fail if such hotspots are not constantly emitting methane. In 
such cases, a random walk survey may leave a misleading picture if the temporal dynamics of the methane emissions are unknown.

This is specifically the case in arctic lakes, where methane is expected to be produced in the anoxic lake bottom sediments. Due to thermal stratification of the waters (warmer waters on top of cold bottom waters), even high methane production at the bottom may not automatically lead to high emissions at the lake surface due to lack of mixing in the lake. Hence, a systematic sampling over longer time periods is essential to quantitatively measure the potentially short periods of high methane emissions during specific mixing or turnover events (e.g., as caused by cold front passages; MacIntyre et al., 2009). Similarly, it has been shown for soil $\mathrm{N}_{2} \mathrm{O}$ fluxes that careful consideration of spatial autocorrelation is necessary to obtain a representative flux estimate from a given area (Folorunso and Rolston, 1984).

Such systematic sampling measurements are still rather costly, and hence we carried out a field experiment with a low-cost solid-state sensor that recently appeared on the market, to explore its suitability for preliminary studies that aim to find locations where episodic high $\mathrm{CH}_{4}$ effluxes would justify the investment for an in-depth study with state-of-theart gas analyzers. Low cost in this context means that the solid-state sensor alone costs less than $€ 40$. A rough calculation of the scalar footprint (Schmid, 1994) for a concentration measurement made with a low-cost sensor at $1 \mathrm{~m}$ above ground level in the arctic moist acidic tussock tundra (with a roughness length of $5.6 \pm 0.9 \mathrm{~cm}$; see Eugster et al., 2005) suggests that such a sensor should show a response to hotspots within ca. $1300 \mathrm{~m}$ upwind under neutral atmospheric stratification. Hence, it is envisaged that with an appropriate sampling design such low-cost sensors could be placed in a regular grid with $\approx 1 \mathrm{~km}$ spacing to identify times, duration, and approximate locality of hotspots at the landscape scale.

\section{Material and methods}

\subsection{The TGS 2600 gas sensor}

The Taguchi Gas Sensor (TGS) 2600 (Figaro Engineering Inc., Osaka, Japan) is a low-power consumption highsensitivity gas sensor for the detection of air contaminants such as those typical for cigarette smoke (Figaro, 2005a). The general field of application of TGS sensors is leak detectors of toxic and explosive gases (Figaro, 2005b). In the case of methane, the risk of explosion starts at concentrations around $4.4 \%$, which is orders of magnitude higher than ambient concentrations around $1.8 \mathrm{ppm}$ (Forster et al., 2007), and hence such solid-state sensors were not sensitive enough for measurements in ambient air. For example, Wong et al. (1996) reported on earlier TGS sensors that showed almost negligible change in response to non-polar gases such as hy- drogen and methane. A few years later, Brudzewski (1998) reported that an older TGS 813 reacted to pulses of air and methane ranging between $1600 \mathrm{ppm}$ and $4000 \mathrm{ppm}$, but not at ambient concentrations $(\approx 1.8 \mathrm{ppm})$. Also, the NGM 2611 methane sensor used by Tümer and Gündüz (2010) is only sensitive to $\mathrm{CH}_{4}$ in the range $1000-10000 \mathrm{ppm}$. To the best of our knowledge, the TGS 2600 is the first sensor for which the manufacturer indicates a sensitivity to methane even in the ppm range (Fig. 1a). Besides methane, a sensitivity to carbon monoxide, iso-butane, ethanol and hydrogen is reported by the manufacturer (Figaro, 2005a).

In addition, Kotarski et al. (2011) report a successful application to detect scents of lemon, musk, pine, and melissa. Ferri et al. (2009a) reported that their tests with the TGS 2600 were in good agreement with the manufacturer's datasheet (Figaro, 2005a), and they also confirm a good time response of the sensor to prescribed variations in $\mathrm{H}_{2}$ concentrations in the air. Additional laboratory tests were carried out by De Marcellis et al. (2009) and Morsi (2007, 2008), but no field deployments have been made to test the sensor's performance and suitability for preliminary studies. We use this terminology explicitly to specify that we do not expect such a low-cost multi-gas sensor to provide the basis for studies that require accurate and precise concentration information, but we do expect a potential for suitable use in preliminary studies such as described above.

\subsection{Principle of operation}

The TGS sensors are solid-state sensors mounted in a TO5 package containing a metal oxide as the sensing material, such as $\mathrm{SnO}_{2}$ (Figaro, 2005b). According to Ferri et al. (2009b), however, the metal oxide used for the TGS 2600 sensor is $\mathrm{TiO}_{2}$. This metal oxide, in the form of granular micro-crystals, is heated to a high temperature at which oxygen in the air is adsorbed to the crystal surface (Figaro, 2005b). In this configuration the sensor has a certain resistance $R_{0}$ in clean air, which is reduced under the presence of a gas to which the TGS sensor is sensitive. This reduced resistance $R_{\mathrm{S}}$ can be expressed by a power function (Figaro, 2005b):

$R_{\mathrm{S}}=A[C]^{-\alpha}$,

where $R_{\mathrm{S}}$ is the actual sensor resistance, $A$ is a coefficient for the gas at concentration $[C]$, and $\alpha$ is the slope of the curve as shown in Fig. 1a. For the application in this study, we measured $R_{\mathrm{S}}$ in a simple electronic circuit where the voltage drop over a precision resistor $R_{L}$ in series with $R_{\mathrm{S}}$ was measured (Fig. 2).

From such a set-up, the sensor resistance can be determined as (Figaro, 2005a):

$R_{\mathrm{S}}=\frac{V_{c} \times R_{L}}{V_{\text {out }}}-R_{L}$ 

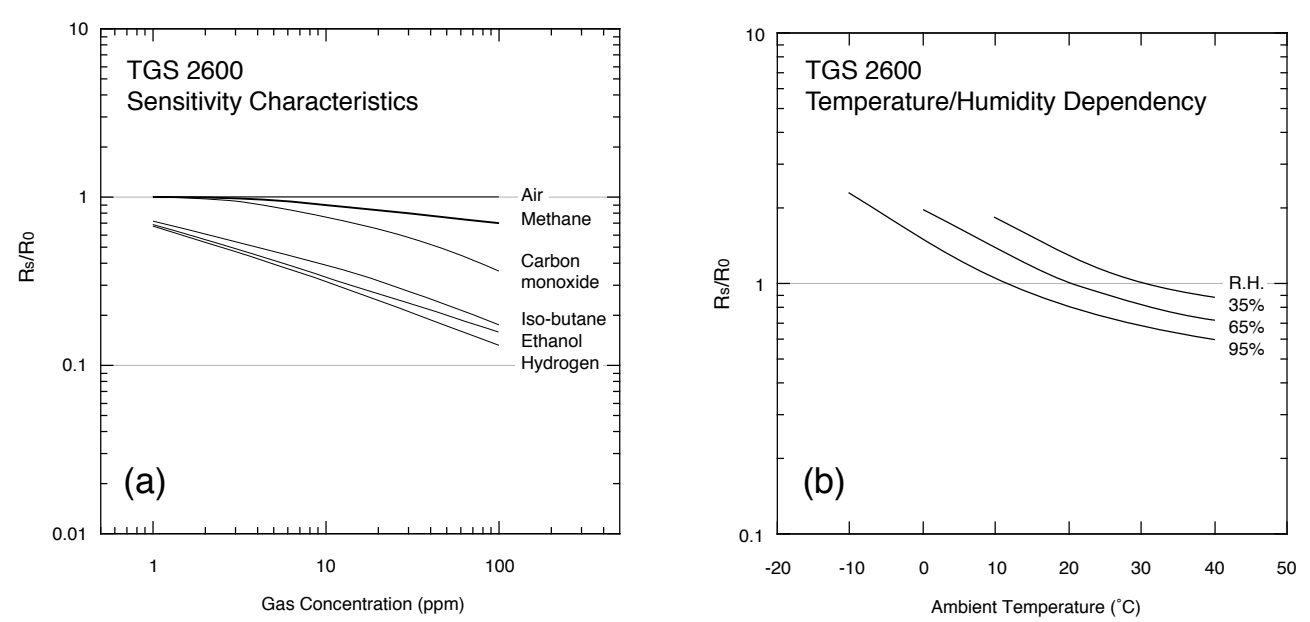

Fig. 1. General Figaro TGS 2600 sensor response (a) and sensitivity to temperature and relative humidity (b) according to manufacturer specifications. $R_{\mathrm{S}} / R_{0}$ is the ratio between sensor resistance $\left(R_{\mathrm{S}}\right)$ under presence of a specific component in relation to the reference resistance $\left(R_{0}\right)$ in "fresh" air without any of the additional chemical components. Modified from Figaro (2005a).

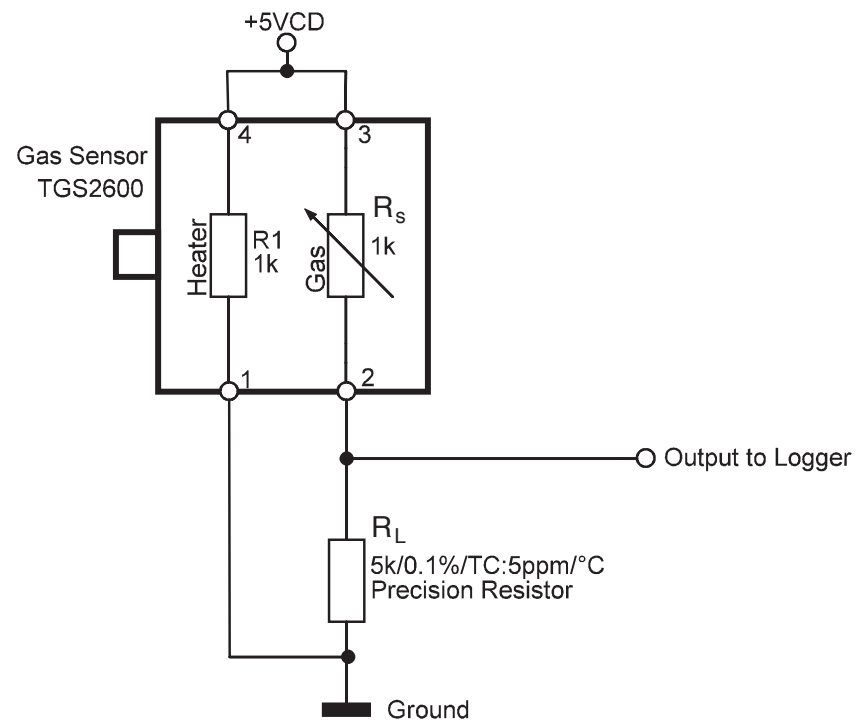

Fig. 2. Sensor configuration used in this study. The variable sensor resistance $R_{\mathrm{S}}$ was measured between pins 2 and 3 and converted to a measurable voltage using an $R_{L}=5 \mathrm{k} \Omega$ precision resistor.

where $V_{c}$ is the supply voltage of $5.0 \mathrm{VDC}$, and $V_{\text {out }}$ is the voltage measured over the precision resistor $R_{L}$. Finally, the ratio between the actual sensor resistance $R_{\mathrm{S}}$ and the cleanair resistance $R_{0}$ is the sensor signal of interest to deduce methane concentrations (Fig. 1).

The main problem to overcome is the sensor's sensitivity to ambient temperature and relative humidity (Fig. 1b), for which only an empirical approach for correction is suggested by the manufacturer (Figaro, 2005b) which includes three steps: (1) identify the range of ambient temperature and humidity expected in the application, (2) obtain sensitivity curves for the target gas, and (3) apply a correction to ap- proximate the average curve. Because this sensor is a multigas sensor primarily used in cigarette smoke detectors, there is a multitude of potential cross-sensitivities to gases other than $\mathrm{CH}_{4}$; this aspect will be discussed in detail in Sect. 4 .

\subsection{Data acquisition and ancillary measurements}

The TGS 2600 sensor signals were recorded by a Campbell Scientific CR3000 data logger, which also measured temperature and relative humidity using a Campbell Scientific sensor model CS215-L12. Its temperature sensor has an accuracy of $\pm 0.4 \mathrm{~K}$ over the range +5 to $+40^{\circ} \mathrm{C}$, which increases to $\pm 0.9 \mathrm{~K}$ over the full measurement range -40 to $+70{ }^{\circ} \mathrm{C}$. Relative humidity is accurate to within $\pm 2 \%$ in the range $10-90 \%$, and increases to $\pm 4 \%$ at the extremes of the range. Atmospheric pressure was measured with a Vaisala PTB110 barometer with an uncertainty of $\pm 0.15 \mathrm{hPa}$. Laboratory tests were carried out with a Campbell Scientific CR510 data logger, both using a single-ended measurement that resolves voltage signals with $666 \mu \mathrm{V}$ resolution in the range $\pm 2500 \mathrm{mV}$, and using a differential voltage reading in the range $\pm 250 \mathrm{mV}$ with a resolution of $33.3 \mu \mathrm{V}$ relative to a $1150 \mathrm{mV}$ reference signal. Test measurements were carried out every $5 \mathrm{~s}$ and stored in the internal memory. In the field, measurements were carried out every $10 \mathrm{~s}$ from which 1min averages were computed and stored on the data logger's CF card.

\section{$2.4 \mathrm{CH}_{4}$ reference measurements}

Field measurements with two TGS 2600 were made in parallel with a Los Gatos Research (Mountain View, CA, USA) Fast Methane Analyzer (FMA-100, serial number 090057) on a moored floating platform on Toolik Lake, Alaska $\left(68^{\circ} 37^{\prime} 52^{\prime \prime} \mathrm{N}, 149^{\circ} 36^{\prime} 10^{\prime \prime} \mathrm{W}, 720 \mathrm{~m}\right.$ a.s.l.). The primary 
purpose of this analyzer was to measure methane fluxes from the lake with the eddy covariance method (Eugster and Plüss, 2010). Air was drawn through the analyzer by a Varian 600 Tri Scroll pump, and data were digitally recorded at $20 \mathrm{~Hz}$, from which 1 min averages were computed for comparison with the TGS 2600 measurements. In addition, the analog output of the FMA-100 was also recorded on the CR3000 data logger to allow the synchronization of the digital data from the FMA-100 with the analog TGS 2600 data. The FMA-100 is an integrated off-axis cavity ringdown spectrometer working at a cell pressure around 138 Torr. The instrument used here (model number 908-0001-0003, serial number 09-0057) has a minimum noise level of $0.26 \mathrm{ppb}$ (1.4 ppb for $1 \mathrm{~s}$ integration times) as determined from Allan variance analysis (Werle, 2010). Its suitability for highquality atmospheric concentration and flux measurements has been demonstrated by Eugster and Plüss (2010) and Tuzson et al. (2010), among others. Concentration calibration checks were always within the uncertainty of the calibration tank available at Toolik Field Station (1.894 ppm $\pm 5 \%$ ).

\subsection{Uncertainty assessment}

The uncertainty in $\mathrm{CH}_{4}$ concentrations that are a result of inaccuracies in the measurements of air temperature and relative humidity are assessed via bootstrapping (Efron, 1979) using the boot procedure of the R statistical software (R Development Core Team, 2010). We chose a parametric bootstrapping approach in which we simulated (a) random uncertainties in both temperature and relative humidity specified by a normal distribution with mean zero and standard deviation according to sensor specifications given above, and (b) systematic deviations of $\pm 4 \mathrm{~K}$ in temperature and/or $\pm 5 \%$ in relative humidity. Relative humidity was kept within the boundaries of 0 to $100 \%$, whereas no limits were set for temperature perturbations. Bootstrapping statistics were obtained from 500 replications.

\section{Results}

The relevant measurement signal is the ratio between the sensor resistance under presence of methane and other trace gases $\left(R_{\mathrm{S}}\right)$ in relation to the sensor resistance under absence of these gases $\left(R_{0}\right)$. All attempts to directly use the voltage signal from the sensor as a measure for $\mathrm{CH}_{4}$ concentration failed because in such a simple approach only $\approx 1 \%$ of the total variance was due to methane. Successful, however, was the approach to first convert all measured $V_{\text {out }}$ voltage signals to sensor resistances $R_{\mathrm{S}}$ according to Eq. (2). We used a precision resistor $R_{L}=5 \mathrm{k} \Omega$ and a stabilized supply voltage $V_{c}$ of 5.0 V DC (Fig. 2).

Next we quantified the reference resistance $R_{0}$ that would result from clean-air measurements without $\mathrm{CH}_{4}$. In principle, this should be feasible with artificial gas mixtures, but

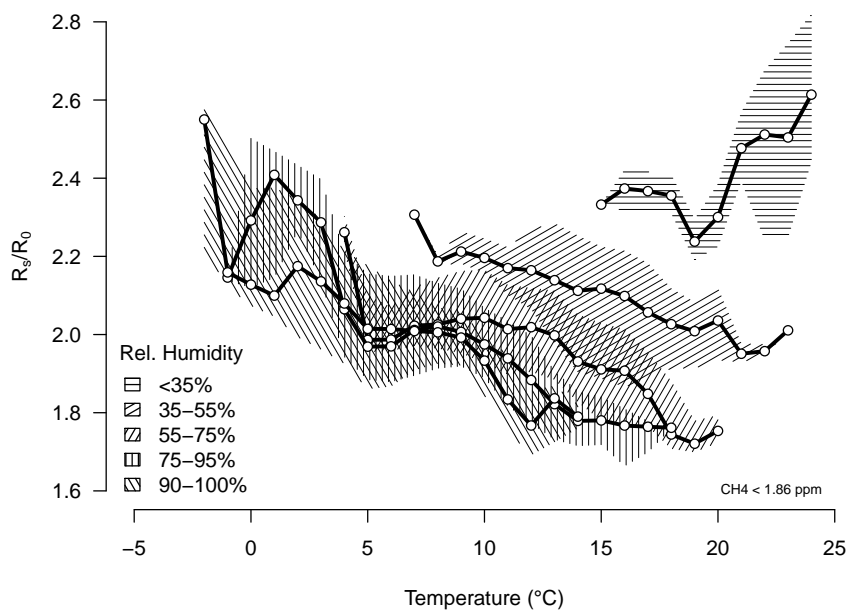

Fig. 3. Observed sensor sensitivity to ambient temperature and relative humidity at $\mathrm{CH}_{4}$ concentrations $<1.86 \mathrm{ppm}$ during the full 2011 field season at Toolik Lake. At relative humidities $\geq 35 \%$, the sensor resistance ratio follows the expected curves in Fig. $1 \mathrm{~b}$ with an offset, but if the air is too dry (relative humidity $<35 \%$ ), the sensor does not provide reliable data that could be used to quantify $\mathrm{CH}_{4}$ concentrations. Each curve and shaded area shows the binned median and interquartile range, respectively, of the selected range of relative humidities (see legend). Temperature bins were chosen $2{ }^{\circ} \mathrm{C}$ wide with $50 \%$ overlap.

as can be seen in Fig. 1b, there is such a strong dependence on temperature and relative humidity that it is not surprising that dry gas standards cannot be used. The manufacturer consequently defined $R_{\mathrm{S}} / R_{0}=1$ for a relative humidity of $65 \%$ and a temperature of $20^{\circ} \mathrm{C}$ (Figaro, 2005a, see also Fig. 1b). This means that the sensor must be considered a relative indicator for $\mathrm{CH}_{4}$ concentrations, and hence we can simply replace $R_{0}$ by the minimum $R_{\mathrm{s}}$ that we find in our data. Hence, we set $R_{0}$ to the sensor resistance at background levels of $\mathrm{CH}_{4}$ at the given temperature and relative humidity that existed when this minimum $R_{0}$ was observed. This means that we obtain $R_{\mathrm{S}} / R_{0} \geq 1$ by definition, which is similar to what the manufacturer specifies, but with an offset to allow us to relate sensor output to absolute concentrations.

\subsection{Sensitivity to relative humidity and temperature}

Figure 3 shows the dependence of $R_{\mathrm{S}} / R_{0}$ on temperature and relative humidity for the whole field season 2011, which generally follows the expected pattern for relative humidity ranging between 35 and $100 \%$. At relative humidity below $35 \%$, however, the sensor no longer obeyed the general rule that shows decreasing $R_{\mathrm{S}} / R_{0}$ with increasing temperatures if relative humidity was kept in a narrow range (that is, 16-35\% in our case). That the manufacturer does not mention how the sensor should behave at relative humidity below $35 \%$ (see Fig. 1b) is an indication that the sensor does not provide reliable information at lower atmospheric moisture levels, and 
our experience suggests that even at $35 \%$ relative humidity the sensor response is not as predictable as the manufacturer specifies. We excluded conditions with relative humidity $<40 \%$ from further analysis.

To determine which factors actually influence the sensor signal, we carried out an analysis of variance using $R_{\mathrm{S}} / R_{0}$ as the response variable, and methane concentration, linear trend of the sensor signal over time, relative humidity and air temperature as predictor variables (Table 1). This analysis indicated that over the full season 2011 more than one third $(36 \%)$ of the variance is simply attributable to the linear trend of the sensor signal, and the expected temperature and relative humidity accounted for another $34 \%$ of the variance. This means that random variations in methane concentrations are only responsible for $18 \%$ of the signal variation seen in our time series.

Although the linear trend is most important, it is essential for practical reasons to first correct for relative humidity and temperature effects, after which the corrected $R_{\mathrm{S}} / R_{0}$ can be translated to methane concentrations. Once the translation is complete, the linear trend associated with the instrument drift (and not with the true seasonal trend) can be removed in a last step. Using this procedure would simplify the calibration requirements; it would be sufficient to take an air sample at the beginning and at the end of a deployment period (e.g., as long as one season according to results from our field experiment), analyze these samples by standard gas chromatography or laser absorption spectroscopy, and use the two calibration points for removal of the temporal trend.

\subsection{Removing relative humidity and temperature sensitivities}

In order to estimate one single correction algorithm for the TGS 2600 sensors in general, we used the information in Fig. $1 \mathrm{~b}$, digitized the curves in $10^{\circ} \mathrm{C}$ intervals, and then fitted the following trend surface to the manufacturer's specification:

$$
\begin{aligned}
\frac{R_{0}}{R_{\mathrm{S}}} & =(0.024 \pm 0.032)+(0.0072 \pm 0.0004) \cdot \mathrm{rH} \\
& +(0.0246 \pm 0.0007) \cdot T_{\mathrm{a}},
\end{aligned}
$$

( $n=11$, adjusted $R^{2}=0.9913$ ) with $\mathrm{rH}$ relative humidity in percent, and $T_{\mathrm{a}}$ air temperature in ${ }^{\circ} \mathrm{C}$. To test whether this approximation can be used for our sensors, we used an iterative procedure to remove the offset in $R_{\mathrm{S}} / R_{0}$ as we defined it, and then obtained best fits for the $\mathrm{rH}$ and $T_{\mathrm{a}}$ terms for an intercept that matches the one in Eq. (3). This yielded adjusted $R^{2}$ of 0.6337 and 0.7425 for sensors 1 and 2, respectively. The coefficients for $\mathrm{rH}$ were $0.0085 \pm 0.0004$ and $0.0076 \pm 0.0003$, and those for $T_{\mathrm{a}}$ were $0.0408 \pm 0.0014$ and $0.0369 \pm 0.0010$ for sensors 1 and 2, respectively. This shows that there are some differences in individual sensors that must be kept in mind, but for the purpose of using this sensor as a proxy for $\mathrm{CH}_{4}$ concentrations in preliminary studies, this is acceptable.
To remove the contribution of $\mathrm{rH}$ and $T_{\mathrm{a}}$ from our $R_{\mathrm{S}} / R_{0}$ signals, we must recall that we used a hyperbolic approach in Eq. (3), and that the relevant information is not the absolute signal but its ratio relative to clean air at the same temperature and humidity. Hence, we remove $\mathrm{rH}$ and $T_{\mathrm{a}}$ by computing a corrected ratio $\left(R_{\mathrm{S}} / R_{0}\right)_{\text {corr }}$ :

$$
\left(\frac{R_{\mathrm{S}}}{R_{0}}\right)_{\text {corr }}=\frac{R_{\mathrm{S}}}{R_{0}} \cdot\left(0.024+0.0072 \cdot \mathrm{rH}+0.0246 \cdot T_{\mathrm{a}}\right) .
$$

\subsection{Conversion to $\mathrm{CH}_{4}$ concentrations}

As already mentioned, it is only practical to remove the linear trend in our data if we can compare methane information obtained from an independent sample with our sensor data; with this independent information we can convert our ratio of resistances to $\mathrm{ppm} \mathrm{CH}_{4}$. Using a linear regression approach with our reference $\mathrm{CH}_{4}$ concentrations from the FMA, we obtained the following equation to convert our signal to $\left[\mathrm{CH}_{4}\right]_{\text {raw }}$ :

$$
\begin{aligned}
{\left[\mathrm{CH}_{4}\right]_{\mathrm{raw}} } & =(1.8280 \pm 0.0005) \\
& +(0.0288 \pm 0.0002) \cdot\left(\frac{R_{\mathrm{s}}}{R_{0}}\right)_{\text {corr }} .
\end{aligned}
$$

For the sake of simplicity, we start with an offset of 1.8 and a multiplier of 0.1 for a given sensor for which we have no better calibration yet, $\left[\mathrm{CH}_{4}\right]_{\text {raw }} \approx 1.8+0.1 \cdot\left(R_{\mathrm{s}} / R_{0}\right)_{\text {corr }}$, and then apply a calibration as described in what follows.

\subsection{Calibrating $\mathrm{CH}_{4}$ concentrations}

To simulate a typical field experiment where there is no reference gas analyzer running in parallel, we arbitrarily selected the data from the first hour of the second day ( $24 \mathrm{~h}$ period) after the sensors were installed to obtain a calibration reference from the FMA at the beginning of the season. The same was done at the end of the season, using the hour starting $24 \mathrm{~h}$ before the end of deployment to obtain a final calibration point.

Before we applied the calibration points to remove the linear trend from our data, we investigated time lags between the TGS 2600 sensor and the FMA reference. Although it is very clear that the TGS 2600 has a slower response than the FMA, we could not find a consistent and relevant time lag to be considered in such a calibration approach.

The real seasonal trend measured (under absence of instrument drift) by the FMA during almost 9 weeks of deployment was $0.00563 \mathrm{ppm}^{\text {week }}{ }^{-1}$, whereas our sensors 1 and 2 (including the respective sensor drift) had 0.0156 and $0.0140 \mathrm{ppm}$ week $^{-1}$, respectively. This indicates that the trend in sensor signals increased above the real seasonal trend by 0.010 and 0.008 ppm week $^{-1}$, which must be taken in account if it is not possible to obtain an initial and a terminal calibration point over a period of deployment of a TGS 2600. 
Table 1. Analysis of variance of the $\mathrm{CH}_{4}$ sensor resistance $R_{\mathrm{S}} / R_{0}$ for Toolik Lake, summer 2011.

\begin{tabular}{lrrrrrr}
\hline Source of variation & Df & Sum Sq & Mean Sq & $F$ value & $\operatorname{Pr}(>F)$ & Expl. Variance \\
\hline Time trend & 1 & 2825.29 & 2825.29 & 252590 & $<2.2 \times 10^{-16 * * *}$ & $36.1 \%$ \\
Relative humidity & 1 & 1668.82 & 1668.82 & 149198 & $<2.2 \times 10^{-16 * * *}$ & $21.3 \%$ \\
Methane concentration & 1 & 1409.8 & 1409.8 & 126041 & $<2.2 \times 10^{-16 * * *}$ & $18.0 \%$ \\
Air temperature & 1 & 996.4 & 996.4 & 89081 & $<2.2 \times 10^{-16 * * *}$ & $12.7 \%$ \\
Residual variation & 82976 & 928.11 & 0.01 & & & $11.9 \%$ \\
\hline Total & 82980 & 7828.42 & & & & $100.0 \%$ \\
\hline
\end{tabular}

Including this correction for the trend based on a calibration at the beginning $\left(\left[\mathrm{CH}_{4}\right]_{\mathrm{raw}, 1}\right.$ and $\left.\left[\mathrm{CH}_{4}\right]_{\mathrm{ref}, 1}\right)$ and at the end $\left(\left[\mathrm{CH}_{4}\right]_{\mathrm{raw}, 2}\right.$ and $\left.\left[\mathrm{CH}_{4}\right]_{\mathrm{ref}, 2}\right)$ of a deployment period, the final corrected TGS 2600 concentration $\left[\mathrm{CH}_{4}\right]_{\text {corr }}$ becomes:

$$
\begin{aligned}
{\left[\mathrm{CH}_{4}\right]_{\text {corr }} } & =\left[\mathrm{CH}_{4}\right]_{\mathrm{raw}}+\left(1-\frac{t}{\Delta t}\right) \cdot\left(\left[\mathrm{CH}_{4}\right]_{\mathrm{ref}, 1}-\left[\mathrm{CH}_{4}\right]_{\mathrm{raw}, 1}\right) \\
& +\left(\frac{t}{\Delta t}\right) \cdot\left(\left[\mathrm{CH}_{4}\right]_{\mathrm{ref}, 2}-\left[\mathrm{CH}_{4}\right]_{\mathrm{raw}, 2}\right)
\end{aligned}
$$

where $t$ is the elapsed time since the initial calibration time point, and $\Delta t$ is the time difference between the terminal calibration and the initial calibration in the same time units.

\subsection{Comparison with reference instrument}

After all corrections were applied, we obtained a relatively good agreement with our reference instrument for both sensors (Fig. 4). There was, however, one period starting around 28-29 June where both TGA 2600 sensors deviated consistently from the reference instruments for several days. Although this period may have been related to smoke from wildfires (even though no smoke was observed), it was also very cold at this time with the first relevant snow fall at Toolik and in large parts of Alaska (Angeloff et al., 2011).

In the second part of the season, both TGA 2600 sensors closely followed the reference concentrations, albeit with a certain reduction in peak concentrations compared to the reference measurements; the most notable of these deviations occurred 27 and 28 July, and 3, 10, and 14 August (Fig. 4). Although the general information on the seasonal and diurnal patterns in $\mathrm{CH}_{4}$ can be seen in Fig. 4, the pairwise agreement of all data points from the TGA 2600 with the reference concentration is only $R^{2}=0.195$ and 0.191 , respectively, for sensors 1 and 2. This low statistical agreement can be misleading because the general diurnal pattern of $\mathrm{CH}_{4}$ was quite accurately resolved (Fig. 5), both in terms of change over time and absolute concentrations. A fast Fourier transform (FFT) analysis of the frequency dependence of the performance of the TGA 2600 in relation to the reference instrument (Fig. 6) indicates that variations in methane occurring at a frequency lower than once per $6 \mathrm{~h}$ are captured rather well, whereas variations that occur at frequencies greater than once per hour are only partially captured $(\approx 50 \%)$ by the TGA 2600 . Hence, in principle the diurnal cycle should be resolvable despite the fact that we only were able to obtain good agreement for average diurnal cycles obtained over many days, not for individual days. The systematic deviations between instruments seen on some days (Fig. 4) tend to show a slightly earlier timing of the early morning peak, a less steep decrease in concentrations during the morning until $9 \mathrm{~h} \mathrm{ADT}$, and a surprising daily minimum around $21 \mathrm{~h}$ ADT for the TGA sensors. This was not simply a time lag due to a long hysteresis of the TGA sensors. In fact, Ferri et al. (2009b) found a relatively fast time response for a TGS 2600 probed with step-changes in $\mathrm{H}_{2}$ concentrations, to which the sensor reacted within a few minutes (their Fig. 11). The fact that we were unable to resolve individual diurnal cycles reflects the present limitations of the low-cost TGS 2600 sensor for more detailed studies, while showing that the sensors can still capture the essential pattern of diurnal changes in $\mathrm{CH}_{4}$ concentrations. We also assume that if the airflow into the TGA 2600 was not passive but instead pumped (as was done with the LGR), the resolution of signals at higher frequencies would improve, especially at times when wind speeds are low.

\section{Discussion}

Because smoke is associated with high levels of $\mathrm{CO}$ to which the TGS 2600 is sensitive according to Figaro (2005a), there is some risk of confounding effects in areas where wildfire or other burning is present. However, during summer 2011, it appears that the uncertainty of the behavior of the TGS 2600 at cold temperatures (around freezing and below) led to the largest discrepancies with the reference concentration measurements. At least there were no reports of smoke or related odors at the site during this period. Morsi (2007) even claim that the TGS 2600 sensor is sensitive to $\mathrm{CO}_{2}$, whereas the manufacturer does not mention a sensitivity for $\mathrm{CO}_{2}$. They however do not explain why and how this sensor should respond to $\mathrm{CO}_{2}$, but if this were true, it would seriously limit the usefulness of the application of the TGS 2600 for $\mathrm{CH}_{4}$ measurements. To test for this potential limitation, we performed an additional ANOVA that included our 


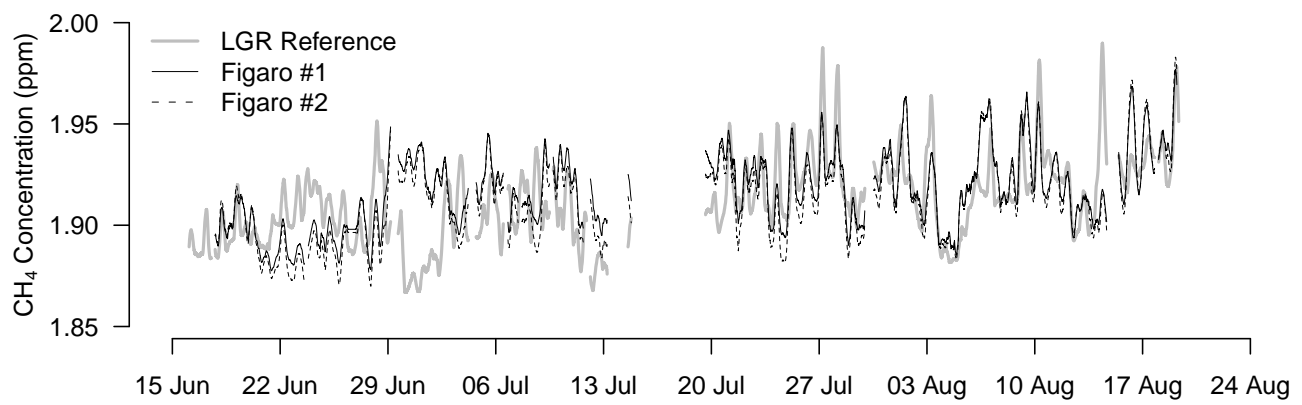

Fig. 4. Seasonal course of $\mathrm{CH}_{4}$ concentration measurements over Toolik Lake during the ice-free season 2011. Data from all sensors where smoothed with a 6-h boxcar moving average.

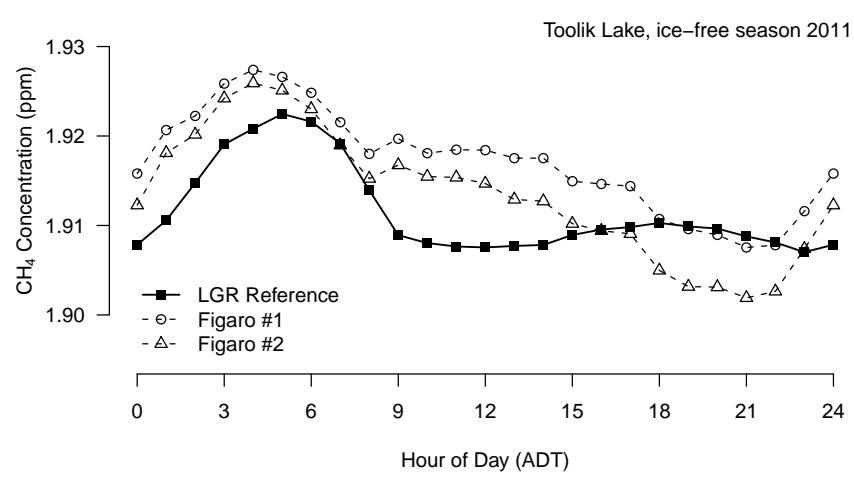

Fig. 5. Mean diurnal cycle of $\mathrm{CH}_{4}$ concentrations over Toolik Lake during the ice-free season 2011. One-minute averages were aggregated by hour of day (Alaska Daylight Time). The standard error of the mean is of the same size as the symbol and hence is not added to the graph. The two low-cost sensors compare well with the Los Gatos Research reference analyzer during the first part of the day and correctly reflect the daily peak concentrations in the near-surface atmosphere.

$\mathrm{CO}_{2}$ concentration measurements that were performed with a closed-path Li-7000 infrared gas analyzer (Licor, Lincoln, NE, USA) and atmospheric pressure. Table 2 summarizes the results which clearly show that $\mathrm{CO}_{2}$ concentrations do not seriously affect the sensor's sensitivity for $\mathrm{CH}_{4}$; the explained variance is $18 \%$ and perfectly matches the result in the ANOVA without $\mathrm{CO}_{2}$ (Table 1). Also, the relative humidity interference $(21.1 \%$ instead of $21.3 \%$ ) and the residual (unexplained) variance (11.8\% instead of $11.9 \%)$ are only marginally affected by $\mathrm{CO}_{2}$. The $3.5 \%$ variance explained by $\mathrm{CO}_{2}$ concentrations is thus simply reducing the explained variance of the temporal trend (strong reduction) and of temperature (an increase from $12.7 \%$ to $18.0 \%$ ). Our interpretation is that this is a purely statistical artifact because (1) $\mathrm{CO}_{2}$ has its own seasonal trend which is, however, negative over the summer season and more in agreement with the sensor drift that we quantified for the TGS 2600, and (2) the diurnal $\mathrm{CO}_{2}$ cycle more strongly follows the diurnal temperature signal since both plant assimilation and respiration are corre-

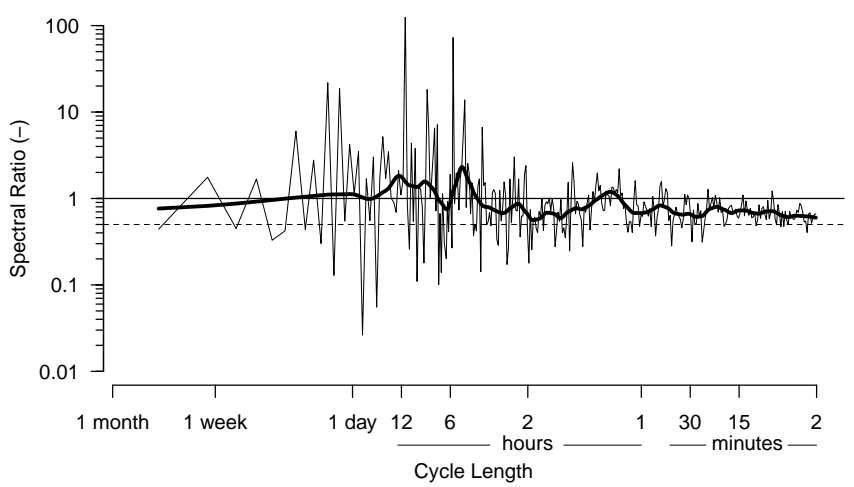

Fig. 6. Spectral densities of solid-state sensor \#2 standardized by those measured by the Los Gatos Research reference analyzer during the longest period without data gaps (30 July to 14 August 2011). Calibrated data aggregated to 1-min averages were fast Fourier transformed, then bin-averaged to 200 bins of equal width on the $\log$ frequency axis, and then expressed as a ratio. The bold line is a local polynomial regression fit (loess function in $R$ with $\alpha=0.12 ; N=22142$ ). Frequencies are labeled with their respective cycle lengths. At cycle lengths $<1 \mathrm{~h}$, the solid-state sensor still captures more than $50 \%$ (dashed line) of the variance of the reference instrument. At cycle lengths $>6 \mathrm{~h}$, a relatively good agreement was found.

lated with temperature; given this, the changes in explained variances in Table 2 are likely unrelated to a cross-sensitivity of the TGS 2600 as was mentioned by Morsi (2007) but not by the manufacturer (Figaro, 2005a).

Although $\mathrm{CO}_{2}$ concentration by itself does not appear to be of concern for $\mathrm{CH}_{4}$ measurements with the TGS 2600, there is typically a tight correlation between $\mathrm{CO}_{2}$ and $\mathrm{CO}$ concentrations if they come from combustion sources. Figure 1a from Figaro (2005a) indicates that the sensor's sensitivity to $\mathrm{CO}$ is similar to that of $\mathrm{CH}_{4}$ for concentrations $<2$ $3 \mathrm{ppm}$. While this is the typical range for ambient $\mathrm{CH}_{4}$ concentrations, the $\mathrm{CO}$ concentrations range between 0.03 and $0.2 \mathrm{ppm}$ (Singh, 1995, p. 22) but can be up to 0.2-0.8 ppm in urban areas during summer months (Singh, 1995). At Point Barrow, which can be considered the best comparison with 
Table 2. Same analysis as in Table 1, but with the inclusion of $\mathrm{CO}_{2}$ concentrations and atmospheric pressure as a potential source of variation.

\begin{tabular}{lrrrrrr}
\hline Source of variation & Df & Sum Sq & Mean Sq & $F$ value & $\operatorname{Pr}(>F)$ & Expl. Variance \\
\hline Time trend & 1 & 2158.31 & 2158.31 & 193894 & $<2.2 \times 10^{-16 * * *}$ & $27.6 \%$ \\
Relative humidity & 1 & 1653.44 & 1653.44 & 148539 & $<2.2 \times 10^{-16 * * *}$ & $21.1 \%$ \\
Methane concentration & 1 & 1409.80 & 1409.80 & 126651 & $<2.2 \times 10^{-16 * * *}$ & $18.0 \%$ \\
Air temperature & 1 & 1407.83 & 1407.83 & 126473 & $<2.2 \times 10^{-16 * * *}$ & $18.0 \%$ \\
$\mathrm{CO}_{2}$ concentration & 1 & 272.37 & 272.37 & 24469 & $<2.2 \times 10^{-16 * * *}$ & $3.5 \%$ \\
Air pressure & 1 & 3.05 & 3.05 & 273 & $<2.2 \times 10^{-16 * * *}$ & $0.04 \%$ \\
Residuals & 82974 & 923.61 & 0.01 & & & $11.8 \%$ \\
\hline Total & 82980 & 7828.41 & & & & $100.0 \%$ \\
\hline
\end{tabular}

Toolik Lake, Cavanagh et al. (1969) found about $0.09 \mathrm{ppm}$ $\mathrm{CO}$, which is far below the concentrations that would require a more careful consideration of $\mathrm{CO}$ as a confounding gas for the TGS 2600 measurements. In urban areas, however, a careful assessment would be needed to establish that the TGS 2600 primarily responds to $\mathrm{CH}_{4}$ and not more strongly to $\mathrm{CO}$.

Other substances that influence the TGS 2600 readings (Fig. 1a) are iso-butane, ethanol, and hydrogen. Iso-butane (R-600a) is an artificial refrigerant $\left(\mathrm{C}_{4} \mathrm{H}_{10}\right)$ that is not expected to pose a serious problem for measurements at remote sites. Similarly, ethanol $\left(\mathrm{C}_{2} \mathrm{H}_{6} \mathrm{O}\right)$ is expected to have extremely low concentrations in the atmosphere because it is so highly soluble in water. Hydrogen $\left(\mathrm{H}_{2}\right)$ is present at $0.6 \mathrm{ppm}$ in the average atmosphere (Singh, 1995), but the sources are mostly anthropogenic and likely can be ignored in the remote arctic tundra. Also, the effect of variations in atmospheric pressure were negligible (Table 2).

Error propagation from inaccurate temperature and relative humidity measurements does not strongly affect $\mathrm{CH}_{4}$ concentration calculations. A systematic error of temperature readings offset by $\pm 4 \mathrm{~K}$ or relative humidity offset by $5 \%$ only marginally affects $\mathrm{CH}_{4}$ concentrations by less than $0.002 \mathrm{ppm}$. The reason is that the calibration step (Sect. 3.4) is the last in the processing chain, and any systematic error introduced in the preconditioning of the raw $\mathrm{CH}_{4}$ signal is corrected within error margins that are clearly below the systematic uncertainty of the solid-state gas sensor. Random errors in temperature and relative humidity measurements are slightly more important; the accuracies of $\pm 0.4 \mathrm{~K}$ for temperature and $\pm 2 \%$ for relative humidity in the typical ambient environment as specified by the manufacturer (see Section 2.3) lead to a mean error of $0.002 \mathrm{ppm}$ and a $95 \%$ confidence interval of 0.002 to $0.003 \mathrm{ppm}$. This influence increases to 0.01 to $0.02 \mathrm{ppm}$ for $\pm 4 \mathrm{~K}$ and $\pm 5 \%$ uncertainties. This is still less than the remaining uncertainty that we found in the final solid-state sensor values which lay within $\pm 0.062 \mathrm{ppm}$ (95\% confidence interval) of the reference instrument. Extreme differences were -0.15 and $+0.10 \mathrm{ppm}$. Although apparently small, these errors are on the same order as the mean diurnal cycle shown in Fig. 5. Depending on objectives for deployment of these sensors, a careful consideration must be given to possible shortcomings in using a low-cost sensor as compared to a high-accuracy instrument. On the other hand, knowing the temporal dynamics, even at lower accuracy, may still provide additional insights as compared to the passive samplers described by Godbout et al. (2006a,b). It should also be mentioned that others (e.g., So et al., 2009) try to combine the aspect of economic costs with high-accuracy in a different way.

\section{Conclusions}

We tested a low-cost solid-state gas sensor (TGS 2600 from Figaro) for its suitability to measure ambient air concentrations of $\mathrm{CH}_{4}$ in the low arctic at Toolik Lake in Alaska, USA, during the ice-free summer season of 2011. Two sensors were run in parallel and compared against a high-quality, offaxis integrated cavity output spectrometer (FMA, Los Gatos Research). The TGS 2600 revealed a high sensitivity for relative humidity and temperature similar to that expected from the specifications by the manufacturer. After corrections for these sensitivities, we obtained a realistic $\mathrm{CH}_{4}$ signal that has the quality for preliminary studies to inspect temporal patterns of $\mathrm{CH}_{4}$ concentrations, which could then inform the decision on whether a considerably more expensive instrument should be deployed for high-accuracy concentration measurements. One realistic approach would be to install such low-cost sensors in a regular grid with $\approx 1 \mathrm{~km}$ spacing to cover a landscape of interest, which could identify times, duration, and approximate locality of hotspots at the landscape scale.

In the seasonal average the TGS 2600 provided realistic insight into the temporal dynamics of $\mathrm{CH}_{4}$ over Toolik Lake and also reproduced the average diurnal cycle of $\mathrm{CH}_{4}$ with an early morning concentration peak of the correct order of magnitude at approximately the correct time of day. Both the general behavior and the systematic differences from the reference instrument were similar for the TGS sensors. From this experience we suggest that the TGS 2600 can be used for 
preliminary assessment of $\mathrm{CH}_{4}$ concentrations at sites where other gas components to which the sensor is sensitive are absent or at low concentrations, and where relative humidity is typically $>40 \%$. Such conditions are not only found in the low arctic, but also in rural areas of more populated zones where the distance to local $\mathrm{CO}$ sources can be substantial.

Acknowledgements. We acknowledge support received from the Arctic LTER grant NSF-DEB-1026843 including supplemental funding from the NSF-NEON and OPP-AON programs. Gaius R. Shaver (MBL) is acknowledged for initiating the study and supporting our activities in all aspects. We also thank Peter Plüss (ETH Zurich), Jennifer Kostrzewski (University of Michigan) and Dustin Carroll for technical and field assistance, and Dan White (MBL) for logistical support with the boats.

Edited by: P. Werle

\section{References}

Angeloff, H., Moore, B., Fathauer, T., Prechtel, A., and Thoman, R.: Alaskan Weather, Weatherwise, 64, 68-69, 2011.

Brudzewski, K.: An attempt to apply Elman's neural-network to the recognition of methane pulses, Sensor. Actuat. B-Chem., 47, 231-234, doi:10.1016/S0925-4005(98)00028-8, 1998.

Cavanagh, L. A., Schadt, C. F., and Robinson, E.: Atmospheric hydrocarbon and carbon monoxide measurements at Point Barrow, Alaska, Environ. Sci. Technol., 3, 251-257, 1969.

De Marcellis, A., Di Carlo, C., Ferri, G., Stornelli, V., Depari, A., Flammini, A., and Marioli, D.: New low-voltage low-power current-mode resistive sensor interface with $\mathrm{R} / \mathrm{T}$ conversion and DC excitation voltage, in: Proceedings of the 13th Italian Conference On Sensors and Microsystems, 515-520, 2009.

DelSontro, T., McGinnis, D. F., Sobek, S., Ostrovsky, I., and Wehrli, B.: Extreme methane emissions from a Swiss hydropower reservoir: contribution from bubbling sediments, Environ. Sci. Technol., 44, 2419-2425, doi:10.1021/es9031369, 2010.

Dzikowski, M., Klyashitsky, A., Jaeger, W., and Tulip, J.: Open path spectroscopy of methane using a battery operated vertical cavity surface-emitting laser system, Proc. SPIE, 7386, 73861H, doi:10.1117/12.839519, 2009.

Efron, B.: Bootstrap methods: another look at the jackknife, The Annals of Statistics, 7, 1-26, 1979.

Eugster, W. and Plüss, P.: A fault-tolerant eddy covariance system for measuring $\mathrm{CH}_{4}$ fluxes, Agr. Forest Meteorol., 150, 841-851, doi:10.1016/j.agrformet.2009.12.008, 2010.

Eugster, W., Kling, G., Jonas, T., McFadden, J. P., Wüest, A., MacIntyre, S., and Chapin III, F. S.: $\mathrm{CO}_{2}$ exchange between air and water in an arctic Alaskan and midlatitude Swiss lake: importance of convective mixing, J. Geophys. Res., 108, 4362-4380, doi:10.1029/2002JD002653, 2003.

Eugster, W., McFadden, J. P., and Chapin III, F. S.: Differences in surface roughness, energy, and $\mathrm{CO}_{2}$ fluxes in two moist tundra vegetation types, Kuparuk Watershed, Alaska, USA, Arct. Antarct. Alp. Res., 37, 61-67, 2005.

Eugster, W., DelSontro, T., and Sobek, S.: Eddy covariance flux measurements confirm extreme $\mathrm{CH}_{4}$ emissions from a Swiss hy- dropower reservoir and resolve their short-term variability, Biogeosciences, 8, 2815-2831, doi:10.5194/bg-8-2815-2011, 2011.

Ferri, G., De Marcellis, A., Di Carlo, C., Stornelli, V., Flammini, A., Depari, A., Marioli, D., and Sisinni, E.: A CCII-based low-voltage low-power read-out circuit for DCexcited resistive gas sensors, IEEE Sens. J., 9, 2035-2041, doi:10.1109/JSEN.2009.2033197, 2009a.

Ferri, G., Di Carlo, C., Stornelli, V., De Marcellis, A., Flammini, A., Depari, A., and Jand, N.: A single-chip integrated interfacing circuit for wide-range resistive gas sensor arrays, Sensor. Actuat. B-Chem., 143, 218-225, doi:10.1016/j.snb.2009.09.002, 2009 b.

Figaro: TGS 2600 - for the detection of air contaminants, Online product data sheet, http://www.figarosensor.com/products/ 2600pdf.pdf (last access: March 2012), 2005a.

Figaro: Technical information on usage of TGS sensors for toxic and explosive gas leak detectors, Online product information sheet, http://www.figarosensor.com/products/common\% 281104\%29.pdf (last access: March 2012), 2005b.

Folorunso, O. A. and Rolston, D. E.: Spatial variability of fieldmeasured denitrification gas fluxes, Soil Sci. Soc. Am. J., 48, 1214-1219, 1984.

Forster, P., Ramaswamy, V., Artaxo, P., Berntsen, T., Betts, R., Fahey, D. W., Haywood, J., Lean, J., Lowe, D. C., Myhre, G., Nganga, J., Prinn, R., Raga, G., Schulz, M., and Dorland, R. V.: Changes in atmospheric constituents and in radiative forcing, Cambridge University Press, 129-234, 2007.

Gibson, G., van Well, B., Hodgkinson, J., Pride, R., Strzoda, R., Murray, S., Bishton, S., and Padgett, M.: Imaging of methane gas using a scanning, open-path laser system, New J. Phys., 8, 26, 18, doi:10.1088/1367-2630/8/2/026, available at: http://www.njp. org/, 2006.

Godbout, S., Phillips, V. R., and Sneath, R. W.: Passive flux samplers to measure nitrous oxide and methane emissions from agricultural sources, Part 1: Adsorbent selection, Biosyst. Eng., 94, 587-596, doi:10.1016/j.biosystemseng.2006.04.014, 2006a.

Godbout, S., Phillips, V. R., and Sneath, R. W.: Passive flux samplers to measure nitrous oxide and methane emissions from agricultural sources, Part 2: Desorption improvements, Biosyst. Eng., 95, 1-6, doi:10.1016/j.biosystemseng.2006.05.007, 2006b.

Haifang, L., Shisheng, Z., Rui, W., and Keqiang, L.: Remote helicopter-borne laser detector for searching of methane leak of gas line, in: Prognostics and System Health Management Conference (PHM2011 Shenzhen), MU3049, 2011.

Hiller, R., Neininger, B., Brunner, D., Buchmann, N., and Eugster, W.: Aircraft-based methane flux estimates for an agriculturally dominated valley in Switzerland, Geophysical Research Abstracts, 13, EGU2011-7015-1, 2011.

Karapuzikov, A., Ponomarev, Y., Ptashnik, I., Romanovsky, O., Kharchenko, O., and Sherstov, I.: Helicopter lidar project for the remote methane leakage detection based on the TEA $\mathrm{CO}_{2}$ laser radiation harmonics, in: Science and Technology, 1999, KORUS '99, Proceedings, The Third Russian-Korean International Symposium on, Vol. 2, 663-666, doi:10.1109/KORUS.1999.876253, 1999.

Kotarski, M., Smulko, J., Czyzewski, A., and Melkonyan, S.: Fluctuation-enhanced scent sensing using a single gas sensor, Sensor. Actuat. B-Chem., 157, 85-91, doi:10.1016/j.snb.2011.03.029, 2011. 
MacIntyre, S., Fram, J. P., Kushner, P. J., Bettez, N. D., O'Brien, W. J., Hobbie, J. E., and Kling, G. W.: Climate-related variations in mixing dynamics in an Alaskan arctic lake, Limnol. Oceanogr., 54, 2401-2417, 2009.

McGuire, A. D., Chapin, III, F. S., Walsh, J. E., and Wirth, C.: Integrated regional changes in arctic climate feedbacks: Implications for the global climate system, Annu. Rev. Environ. Resour., 31, 61-91, doi:10.1146/annurev.energy.31.020105.100253, 2006.

Morsi, I.: A microcontroller based on multi sensors data fusion and artificial intelligent technique for gas identification, Iecon 2007: 33rd Annual Conference of the IEEE Industrial Electronics Society, Vol. 1-3, Conference Proceedings, 2203-2208, doi:10.1109/IECON.2007.4460098, 2007.

Morsi, I.: Electronic noses for monitoring environmental pollution and building regression model, Iecon 2008: 34th Annual Conference of the IEEE Industrial Electronics Society, Vol. 1-5, Proceedings, 1668-1673, 2008.

R Development Core Team: R: A Language and Environment for Statistical Computing, R Foundation for Statistical Computing, Vienna, Austria, http://www.R-project.org, ISBN 3-900051-070, 2010.

Reeburgh, W. S., King, J., Regli, S., Kling, G., Auerbach, N., and Walker, D.: $\mathrm{A} \mathrm{CH}_{4}$ emission estimate for the Kuparuk River Basin, Alaska, J. Geophys. Res., 103, 29005-29013, 1998.

Schmid, H. P.: Source areas for scalars and scalar fluxes, Bound.Lay. Meteorol., 67, 293-318, 1994.

Schroth, M. H., Eugster, W., Gómez, K. E., Gonzalez-Gil, G., Niklaus, P. A., and Oester, P.: Above- and below-ground methane fluxes and methanotrophic activity in a landfill-cover soil, Waste Manage., 5, 879-889, doi:10.1016/j.wasman.2011.11.003, 2012.

Serreze, M. C. and Francis, J. A.: The arctic amplification debate, Clim. Change, 76, 241-264, doi:10.1007/s10584-005-9017-y, 2006.
Singh, H. B. (Ed.): Composition, Chemistry, and Climate of the Atmosphere, Van Nostrand Reinhold, New York, 527 pp., 1995.

So, S., Sani, A. A., Zhong, L., Tittel, F., and Wysocki, G.: Laser spectroscopic trace-gas sensor networks for atmospheric monitoring applications, in: Proceedings of the 8th ACM/IEEE International Conference on Information Processing in Sensor Networks, vol. ESSA 2009, 1-8, 2009.

Tümer, A. E. and Gündüz, M.: Design of a methane monitoring system based on wireless sensor networks, Sci. Res. Essays, 5, 799-805, 2010.

Tuzson, B., Hiller, R. V., Zeyer, K., Eugster, W., Neftel, A., Ammann, C., and Emmenegger, L.: Field intercomparison of two optical analyzers for $\mathrm{CH}_{4}$ eddy covariance flux measurements, Atmos. Meas. Tech., 3, 1519-1531, doi:10.5194/amt-3-1519-2010, 2010.

Walter, K. M., Zimov, S. A., Chanton, J. P., Verbyla, D., and Chapin III, F. S.: Methane bubbling from Siberian thaw lakes as a positive feedback to climate warming, Nature, 443, 71-75, doi:10.1038/nature05040, 2006.

Werle, P.: Time domain characterization of micrometeorological data based on a two sample variance, Agric. Forest Meteorol., 150, 832-840, doi:10.1016/j.agrformet.2009.12.007, 2010.

Wong, K. K. L., Tang, Z. A., Sin, J. K. O., Chan, P. C. H., Cheung, P. W., and Hiraoka, H.: Sensing mechanism of polymer for selectivity enhancement of gas sensors, ICSE '96 - 1996 IEEE International Conference On Semiconductor Electronics, Proceedings, 217-220, doi:10.1109/SMELEC.1996.616485, 1996.

Zirnig, W., Ulbricht, M., Fix, A., and Klingenberg, H.: Helicopterborne laser methane detection system - a new tool for efficient gas pipeline inspection, in: International Gas Research Conference, Vancouver, Canada, 2004. 